\title{
Noticias sobre tres apostolados pictóricos del primer tercio del siglo XVII localizados en la ciudad de Durango
}

\section{Reports on Three Apostolate Paintings of the First Third of the Eighteenth Century Found in the City of Durango}

Artículo recibido el I4 de febrero de 20I8; devuelto para revisión el 17 de octubre de 20I8; aceptado el 7 de enero de 2019 .

Adolfo Martínez Romero

Línea de investigación

Line of research

Publicación más reciente

Artículos

Resumen

Palabras clave

Abstract

Keywords
Posgrado en Historia del Arte, Universidad Nacional Autónoma de México adolforomeroromero@hotmail.com

El arte en el norte de México.

Art in northern Mexico.

"La enseńanza artística y pictórica de las alumnas del Instituto de Niñas (I870-1900)", Revista Educalia, vol. 7, 2014.

Afortunadamente, dentro de los territorios norteńos se siguen encontrando obras pictóricas del periodo virreinal, sobre todo del siglo XVIII. Éste es el caso de los lienzos que forman parte de tres apostolados: uno firmado por Ventura Miranda, otro de Nicolás Correa y uno más de autoría desconocida. Evidencia de los diversos movimientos que han sufrido los acervos virreinales, razón por la cual hoy dichos lienzos se encontraban en el templo de Nuestra Señora de los Ángeles, construido en la última década del siglo xix.

Durango (México); franciscanos; circulación de las artes; pintores locales; apostolados; convento de San Antonio (México); catedral de Durango (México).

It is to be celebrated that works of pictorial art from the Viceroyalty continue to be found in the northern territories, above all from the eighteenth century. This is the case of the canvases that make up three apostolate paintings: one signed by Ventura Miranda, another by Nicolás Correa and one more of unknown authorship. These apostolates evidence the vicissitudes undergone by collections of the Viceroyalty, an example of which is to be found in the fact that these canvases were in the church of Nuestra Señora de los Ángeles, built in the last decade of the nineteenth century.

Durango, Franciscans, circulation of artworks, local painters, apostolates, convent of San Antonio, cathedral. 
DOI: http://dx.doi.org/10.22201/iie.18703062e.2019.115.2698

ADOLFO MARTÍNEZ ROMERO

UNIVERSIDAD NACIONAL AUTÓNOMA DE MÉXICO

\section{Noticias sobre tres apostolados pictóricos del primer tercio del siglo XVIII, localizados en la ciudad de Durango}

L a ciudad de Durango se convirtió en sede episcopal en I620, a partir de la segregación del obispado de Guadalajara, con el objetivo de que sus instituciones sirvieran como bastión para los intereses de la Corona en cuanto a la apropiación de recursos naturales, el control territorial y administrativo, así como para la evangelización. Sin embargo, esta condición eclesiástica no fue garantía para que los edificios oficiales pudieran culminar su construcción durante esa centuria, debido a que los recursos económicos no fueron suficientes y constantemente provocaron un deterioro en muchos aspectos de la vida. Incluso, los gobernadores abandonaron la ciudad desde I63I para residir en el centro minero — recién descubierto- de Parral, ${ }^{2}$ donde permanecieron por más de cien años. ${ }^{3}$ Fue hasta las primeras décadas del siglo XVIII, cuando el aumento de la población y la recaudación de los diezmos facilita-

I. Clara Bargellini menciona que para un español de los siglos Xviı y XvıII, vivir en la Nueva Vizcaya era vivir en la frontera, y eso era motivo para que la vida citadina y de sus ajuares se agudizara. Clara Bargellini, "introducción” a Los bienes del mayorazgo de los Cortés del Rey en I729, de Gustavo Curiel (Ciudad de México: Universidad Nacional Autónoma de México-Instituto de Investigaciones Estéticas, 1993), 9-II.

2. No sería ilógico pensar que Parral pudo haber sido la sede episcopal si la fundación del obispado hubiera tardado una década más.

3. El primer gobernador en llegar nuevamente a la ciudad fue José Carlos de Agüero en I76I. 
ron la culminación de las obras constructivas de algunos templos en la ciudad, tanto de las órdenes religiosas, como del clero diocesano. Asimismo, el ornato interior de estas iglesias se completó. Este nuevo panorama permitió que la ciudad dejara de ser concebida como parte de un territorio septentrional. Por ejemplo, José de Arlegui en 1724, definidor de la Provincia de San Francisco de Zacatecas y examinador oficial del obispado de Durango calificó, por primera vez, a la ciudad capital como la metrópoli del reino. ${ }^{4}$

Para el estudio de las pinturas que aquí se abordan y que datan de las primeras décadas del siglo XVIII, deben tomarse en cuenta las particularidades que tienen los acervos de la ciudad de Durango. Es decir, a pesar del esplendor de las primeras décadas de esta centuria (I700-I730), actualmente no es posible observar ningún retablo al interior de los templos, como sucede en otras ciudades. Por su parte, las pinturas y las esculturas que fueron parte de estas estructuras están dispersas en varios recintos. En este sentido, el estudio de estos acervos artísticos se complica debido a dos grandes problemáticas: la primera tiene que ver con los escasos documentos históricos acerca del adorno que caracterizó a las iglesias y la segunda, tiene relación con los diversos movimientos que han tenido las pinturas y las esculturas, así como la falta de documentación sobre dichos traslados. ${ }^{5}$

Por ejemplo, son pocas las noticias coloniales sobre el adorno de los recintos religiosos del obispado de Durango y sus objetos, al menos, que han llegado hasta nuestros días, tanto de los conventos como de los templos del clero diocesano. Sólo algunas crónicas tempranas se refieren a la presencia de imágenes religiosas, pero mayormente relacionadas con aquellas que fueron martirizadas en la guerra tepehuana de $1616 .{ }^{6}$ De los templos del clero diocesano no

4. José de Arlegui, Trono salomónico (s.p.i. [ca. 1724]).

5. Estas observaciones están tomadas de la tesis doctoral que estoy realizando en la Facultad de Filosofía y Letras de la Universidad Nacional Autónoma de México, titulada "El acervo pictórico de la catedral de Durango. Siglos Xvir y XviII".

6. Puede decirse que las pocas notas sobre objetos devocionales, hoy considerados artísticos, se refieren a las imágenes martirizadas durante la guerra tepehuana de I6I6, tanto de los jesuitas como de los franciscanos. Véase Andrés Pérez de Ribas, Historia de los triunfos de nuestra fe entre las más bárbaras, y fieras del nuevo orbe, libro X, edición facsimilar, 1645 (México: El Colegio de México, Siglo XXI, 1992), capítulo XIIII; Francisco de Florencia, Zodicaco mariano en que el sol de justicia Christo, con la salud en las alas visita como signos, y casas proprias para beneficio de los hombres los templos, y lugares dedicados a los cultos de su SS. Madre por medio de las más célebres, y milagrosas imágenes de la misma Señora, que se veneran en esta América Septentrional, y reynos de la Nueva España (Ciudad de México: en la nueva imprenta del Real, y más antiguo Colegio de San 


\section{ADOLFO MARTÍNEZ ROMERO}

se conocen más detalles. Las noticias del siglo XviII no son tan distintas a las anteriores. También son muy pocas y mayormente dan cuenta de los objetos devocionales relacionados con las órdenes religiosas en el interior del obispado. Por ejemplo, los datos más conocidos e importantes son los que dio el obispo Pedro Tamarón con motivo de sus visitas pastorales en las que registró, mediante una serie de inventarios, el ajuar de todas las iglesias que visitó, incluida la catedral. ${ }^{7}$ Cabe destacar que estos inventarios no mencionan nada sobre las pinturas, su autoría o época de manufactura, debido a que fueron concebidas como un mero complemento para los retablos. Por el contrario, las esculturas sí fueron atendidas, sobre todo aquellas relacionadas con los franciscanos y jesuitas, debido a que tuvieron mayor devoción. Así, Tamarón se refirió al Señor del mezquital (Mezquital), el Señor de Mapimí (Cuencamé), el Señor de las Minas (Parras), el Señor del Santo Entierro (Santiago Papasquiaro) y el Señor de los Guerreros (San José del Tizonazo, Indé), así como a las esculturas marianas, como la Virgen Gachupina (Topia), la Virgen del Hachazo (El Zape), la Virgen del Mezquital (Mezquital) y la Virgen de la Soledad (Llerena, Zacatecas). Sobre la catedral, el obispo sólo destacó la escultura de la Inmaculada Concepción del altar mayor y no señaló ninguna pintura.

Respecto a la segunda problemática que tienen los acervos artísticos novohispanos de Durango, se puede decir que los traslados que sufrieron desde el siglo XIX son un grave problema para poder identificar el origen de muchas de las piezas pictóricas y escultóricas. Por ejemplo, en el caso de los conventos, hoy se puede observar que la totalidad de sus piezas está dispersa entre los diversos templos que se construyeron desde finales de la centuria decimonónica en la ciudad, así como en la catedral y el Museo Regional. ${ }^{8}$ Para el caso catedralicio, se puede decir que su obra pictórica también se dispersó, pero la diferencia es

Ildefonso, 1755). Disponible en: https://books.google.com.mx/books?id=7Twg55DgAfoC\&prints ec=frontcover\&source=gbs_ge_summary_r\&cad=O\#v=onepage\&q\&f=false, consultado el is de agosto de 20I5; José de Arlegui, Crónica de la provincia de N.S.P.S. Francisco de Zacatecas (Ciudad de México: Cumplido, I85I). Disponible en https://books.google.com.mx/books?id=oorıHsp8SQC\&pg=RAI-PAI38\&lpg=RAI-PAI3 $8 \& \mathrm{dq}=$ chronica + de + la + santa + provincia + de + san + francisco $+a$ rlegui\&source=bl\&ots=q4O_8LCHDR\&sig=SBNRqR6_i93ZW2 mgnqlxI_HPn_Y\&hl=es-4I9\&sa=X \&ved=oahUKEwi2sNrBOP7SAhvH3mMKHfZCDISQ6AEIKjAC\#v=onepage\&q=chronica\%2Ode\%20 la\%2osanta\%2oprovincia\%2ode\%2osan\%2ofrancisco\%2oarlegui\&f=false, consultado el 24 de febrero de 20I4.

7. Archivo Histórico del Arzobispado de Durango (en adelante AHAD), Gobierno y visitas pastorales, caja 2, varios legajos.

8. Esta afirmación parte de mis observaciones en la tesis antes mencionada, véase n. 5. 
que las piezas que salieron de ese sitio fueron aquellas que pertenecieron a los acervos conventuales y que llegaron a la catedral tras la expulsión de los jesuitas en 1767 y el abandono paulatino que los franciscanos hicieron de su convento desde 1856 hasta 1917.

Las investigaciones actuales sobre la pintura del siglo XVIII han puesto mayor atención al tema de la circulación de las artes entre la Ciudad de México y los diferentes centros urbanos del virreinato, entre ellos, los norteńos. Precisamente, en esta región es donde se halla una gran cantidad de pinturas firmadas por los maestros activos durante esos ańos, como Antonio de Torres, Pedro López Calderón, ${ }^{9}$ Francisco Martínez y Juan Francisco Aguilera, entre otros, y en menor medida, obras de los autores que se abordan en este trabajo, como Nicolás de Correa, Ventura de Miranda y los Arellano. Esta presencia se debe sin duda a la construcción y reconstrucción de los templos del obispado de Durango y su capital durante la primera mitad del siglo XviII, lo que provocó una demanda de obras retablísticas, pictóricas y escultóricas.

De manera paralela a esta veta de trabajo que tuvieron los pintores de la capital del virreinato, se ha comenzado a evidenciar que durante las décadas de I680-I730 nació un grupo de artífices en la localidad que también cubrió la demanda en la región. Entiéndase región como el territorio de los actuales estados de Jalisco, Zacatecas, Chihuahua y Durango. Ya Rogelio Ruiz Gomar en sus estudios sobre el norte hace hincapié en que los maestros alarifes debieron haberse trasladado entre estas ciudades. ${ }^{\text {IO }}$ La participación de estos artífices se destacó mayormente en el campo de la arquitectura, ${ }^{\mathrm{II}}$ la retablística ${ }^{\mathrm{I2}} \mathrm{y}$

9. Afortunadamente, la vida y la obra de este pintor comienza a dibujarse. Véase José Armando Hernández Soubervielle, "El celo espiritual y militar de la orden franciscana y la monarquía hispánica en una pintura de la Inmaculada de Pedro López Calderón", Archivo Español de Arte núm. 336 (20II): 337-354. Asimismo, José Ignacio Mayorga Chamorro realiza una tesis sobre Pedro López Calderón en la Universidad de Málaga, España.

Io. Rogelio Ruiz Gomar, "La pintura en el templo de valle de Allende, Chihuahua", en Historia y arte en un pueblo rural: San Bartolomé, hoy Valle de Allende, Chihuahua, coord. Clara Bargellini (Ciudad de México: Universidad Nacional Autónoma de México, I998), I43-200.

II. De esos años, entre los maestros más sobresalientes que se pueden mencionar está Mateo Núñez, quien comenzó los trabajos de reconstrucción de la catedral de Durango a finales del siglo XVII; posteriormente destacaron los maestros Simón de los Santos y José de la Cruz, quienes continuaron con estas obras tras la partida de Núñez.

I2. Por ejemplo, cuando se reconstruyó el templo de San Juan de Dios, se colocó un altar nuevo para la Virgen del Tránsito, el cual fue hecho por Juan Antonio Carreño, maestro proveniente de Sombrerete, Zacatecas. Véase Clara Bargellini, "Escultura y retablos coloniales de la ciudad de 
la carpintería. ${ }^{\mathrm{I}}$ Para el caso de los pintores, aún no se conocen documentos ni obras que señalen que estuvieron activos durante esos años. La única evidencia temprana es la pintura mural de la bóveda del camarín de la Virgen en el templo de Nuestra Señora de los Remedios y el retrato del obispo Martín de Elizacochea que hizo, aunque un poco más tarde, José Gabriel de Ovalle en 1742 cuando estuvo en Durango. ${ }^{\text {I4 }}$

Es muy probable que en poco tiempo, tras las investigaciones que hoy se desarrollan en torno a la pintura de esta primera mitad del siglo xviII, se puedan localizar mayores datos de pintores locales y sus obras. Lo anterior provocará que dichos estudios muestren las deudas y aportaciones pictóricas, producto de la convivencia entre las obras de los maestros de la capital novohispana y la región norteńa, como refieren en cierto sentido Paula Mues, Ilona Katzew, Luisa Elena Alcalá y Jaime Cuadriello cuando advierten que las interacciones y adaptaciones pictóricas durante la centuria dieciochesca pusieron en marcha la difusión artística, reformulación e intercambios en el Virreinato y dieron lugar a formas de expresión locales. ${ }^{15}$

Esta convivencia entre la producción local y las obras enviadas desde la Ciudad de México no mermó el aprecio por la pintura de los maestros capitalinos por parte de la población de Durango, como así lo evidencian algunas noti-

Durango", en Imaginería virreinal: memorias de un seminario, coord. Gustavo Curiel (Ciudad de México: Universidad Nacional Autónoma de México/Instituto Nacional de Antropología e Historia/Secretaría de Educación Pública, 1990), 47-60.

13. Aunque hasta ahora no se tiene registrado ningún pintor activo hacia esas fechas, no sería difícil pronto encontrar noticias al respecto. Por ejemplo, el inventario de I7I3 que se hizo con motivo del arribo a Durango del obispo Pedro Tapiz, los encargados de hacer los avalúos de sus pertenencias fueron personajes de la localidad, entre ellos, Juan González de la Borbolla para la ropa blanca, Francisco Nores para la carpintería, Ignacio Araujo para la platería, Pedro del Muro para la herrería y Pedro de los Ríos para la sastrería.

14. Alejandro Huerta Carrillo, "Análisis químico de las pinturas del pintor zacatecano Gabriel José de Ovalle", Boletín del Instituto Nacional de Antropología e Historia (1993): 63-79; Clara Bargellini, "Gabriel José de Ovalle, pintor en Durango y Zacatecas", Transición, núm. I3 (1993): 44-47; "Amoroso horror: arte y culto en la serie de la pasión de Gabriel de Ovalle de Guadalupe, Zacatecas", en XVIII Coloquio Internacional de Historia del Arte: Arte y violencia (Ciudad de México: Universidad Nacional Autónoma de México-Instituto de Investigaciones Estéticas, 1995), 499-524; Clara Bargellini, "Nuevos documentos sobre Gabriel José de Ovalle", Anales del Instituto de Investigaciones Estéticas, núm. 78 (200I): 77-IO2.

15. Paula Mues, Jaime Cuadriello, Ilona Katzew y Luisa Elena Alcalá, "Painted in Mexico, I700-I790. Pinxit Mexici”, en Painted in Mexico, I700-1790. Pinxit Mexici, ed. Ilona Katzew (Los Ángeles: Los Angeles County Museum of Art, 2017), I6-5I. 
cias. Por ejemplo, se sabe que entre los años de 1719 y I739, cuando se renovó el convento de San Cosme y San Damián, su hospital y su iglesia, se trajeron unos lienzos para el claustro desde la Ciudad de México (1729), mismos que fueron calificados de "valiente pincel". ${ }^{16}$ Ahora, en el templo —único edificio que sobrevivió de este conjunto arquitectónico- hay obras de Francisco Martínez, Antonio de Torres y José de Páez. En una colección particular se encuentra el lienzo de la Virgen del Tránsito, el cual perteneció a la cofradía que estaba instalada en este templo. El lienzo está firmado por José de la Mota en I716. Otra referencia que evidencia la estima de las pinturas de los maestros de la capital del virreinato es la descripción que hizo el obispo Pedro Tamarón de la capilla de San José de Avino en I759. Al respecto dijo que la capilla era "muy buena y nueva, pintada toda y adornada de lienzos finos de uno y otro lado, con su colateral en el medio muy pulido y tallado, todo dorado, dedicado a san José". ${ }^{17}$ Sin duda, se trata de los cuadros de Pedro López Calderón y Antonio de Torres. En este templo se aprecia claramente la alternancia entre las obras de estos afamados pintores y la que hicieron los maestros de la región, debido a que en un costado del altar mayor se encuentra un lienzo del Señor de Zacatecas firmado por Gabriel de Ovalle.

Algunos de los lienzos que se estudian en este trabajo, firmados por Ventura de Miranda, Nicolás Correa y uno de los maestros apellidado Arellano, se localizaron en el templo de Nuestra Señora de los Ángeles de la ciudad de Durango. Este hallazgo se dio a raíz de la tesis doctoral que se realizó sobre el acervo pictórico de la catedral de Durango de los siglos XVII y XVIII, donde se establece el origen de algunas de las piezas mediante la revisión de los múltiples inventarios históricos. Dicha revisión señala la presencia de pinturas provenientes del convento franciscano de Durango, entre ellas, varias de los apóstoles, las cuales pasaron a la catedral en 1917 y después al templo de la Virgen de los Ángeles.

\section{El recinto franciscano y sus bienes artísticos}

No se sabe mucho sobre la situación que vivieron las órdenes religiosas tras la exclaustración de i856. Parece que los franciscanos siguieron ocupando su

I6. Castorena y Ursúa y Sahagún de Arévalo, Gacetas de México (México: Secretaría de Educación Pública, I949-1950), 201.

17. AHAD, Visitas pastorales, caja 2, lib. 35, lib. I de la visita pastoral del obispo Pedro Tamarón, I759-1760. 
convento, donde el abandono y la desolación fueron parte de su cotidianidad, como así lo da a entender el padre Mirablanca en sus escritos. Este personaje llegó a Durango en 1906 para ser el nuevo guardián, sucediendo al padre fray Francisco Mancera. Mirablanca menciona que "puedo asegurar en conciencia que desde el año de 1856 del próximo siglo pasado diecinueve hasta este año de 1906 no se han ocupado, ninguno de los reverendos padres guardianes que se han venido sucediendo en este convento, de hacer inventario de todo lo que existe y existía en este convento". Ante este descuido y descontrol de los bienes, el nuevo guardián decidió levantar un registro más puntual de dichos objetos. Asimismo, ante el deterioro arquitectónico de dicho convento, Mirablanca emprendió algunas obras de remodelación con ayuda del arzobispo Santiago Zubiría y Manzanera, mismas que quedaron asentadas en un pequeño libro inventario desde 1906 hasta $1917 .{ }^{18}$ En este último año los franciscanos abandonaron definitivamente la ciudad y el conjunto conventual fue demolido por orden del general revolucionario Gabriel Gavira.

Por fortuna, la totalidad de los bienes artísticos franciscanos, como pinturas y esculturas pasaron a la catedral, salvándose de una pérdida inminente. Veinte años después los franciscanos volvieron a la ciudad, en 1942, y el entonces arzobispo José María González y Valencia les entregó el templo de Nuestra Señora de los Ángeles y una parte de los bienes artísticos que les había pertenecido. Precisamente, hoy en este templo se encuentran algunos lienzos relacionados con las devociones franciscanas, entre ellos, una serie de la Vida de la Virgen, dos de San Antonio de Padua, el primero de principios del siglo XviII y el segundo pintado en 1897, por Ignacio Barraza, además de un lienzo de San Judas Tadeo, con acusadas influencias villalpandescas, otro de Jesús Cordero y otro de Santa Ana, firmado por Arellano (fig. 9). También en este templo hay dos apostolados incompletos: el primero, autoría de Ventura de Miranda (figs. I-4), y el segundo, anónimo (figs. 5-8), los cuales son objeto de estudio en este trabajo.

Es novedoso encontrar obra de Miranda en el norte, específicamente en Durango, debido a que no se habían hallado pinturas en este territorio. A la fecha sigue siendo un pintor poco conocido en el ámbito académico, debido a la escasa obra que se ha documentado. Sólo se sabe que estuvo activo hacia I723. Manuel Toussaint (I890-I955) en su libro Pintura colonial dio a conocer a algunos pintores a los que agrupó en torno a este apellido y los calificó como

18. AHAD, Inventarios, caja 9, leg. I2, 1906. 


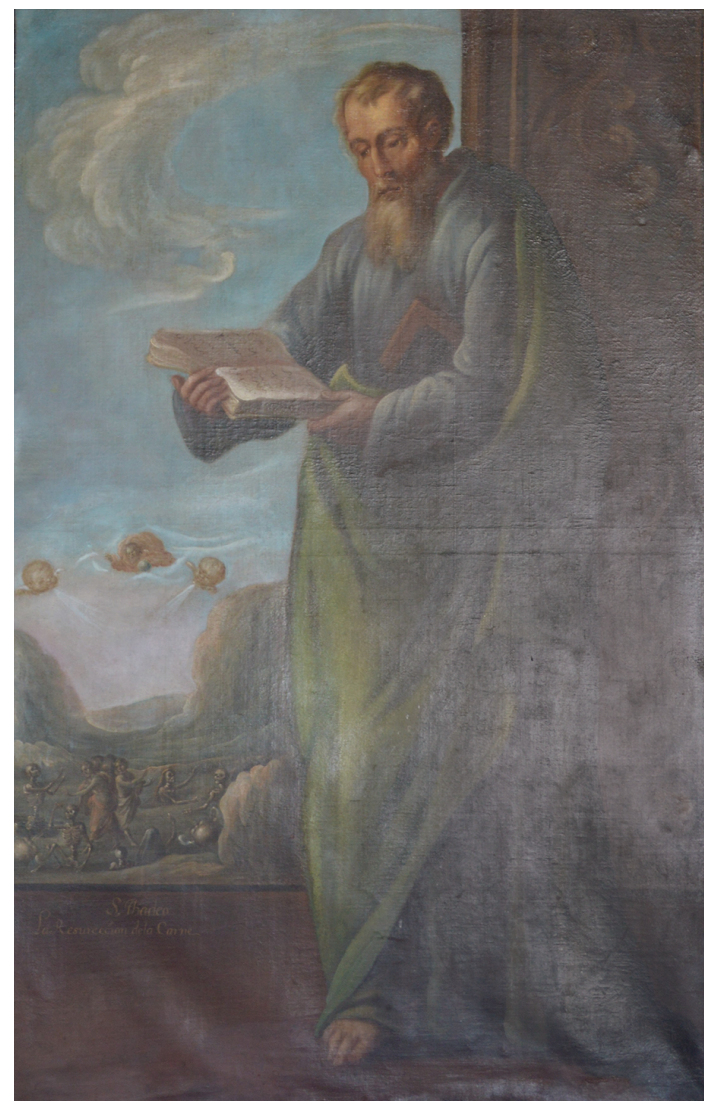

Fig. I. Ventura de Miranda, San Judas Tadeo, primer tercio del siglo XviII, colección del templo de Nuestra Señora de los Ángeles, Durango. Foto: Adolfo Martínez Romero. SECRETARÍA DE CULTURA-INAHMÉx. "Reproducción autorizada por el Instituto Nacional de Antropología e Historia”.

"los Miranda", aunque advierte que no todos ellos pudieran haber pertenecido a una misma línea genealógica. Así, consignó un José Miranda y a un posible hijo suyo llamado de la misma manera. También, retomó el dato de un pintor, igualmente llamado José Miranda, activo en Puebla hacia I7I4 que Pérez Salazar había dado a conocer con anterioridad. Se sabe que este último pintor era castizo e hijo de Francisco de Miranda. ${ }^{19}$ Asimismo, Toussaint registró un Xavier Miranda activo hacia I740, de quien existe obra en el Museo de Churubusco, en la Ciudad de México. Por otro lado, en los datos que anexó Xavier Moys-

19. Manuel Toussaint, La pintura colonial en México (Ciudad de México: Universidad Nacional Autónoma de México, 1990), I45; Francisco Pérez Salazar, Historia de la pintura en Puebla (México: Perpal, 1990), I53. 
DOI: http://dx.doi.org/10.22201/iie.18703062e.2019.115.2698

252

ADOLFO MARTÍNEZ ROMERO

Fig. 2. Ventura de Miranda, San

Juan Evangelista, primer tercio del siglo XviII, templo de Nuestra Señora de los Ángeles, Durango. Foto: Adolfo Martínez Romero. SECRETARÍA DE CULTURA-INAHMÉx. "Reproducción autorizada por el Instituto Nacional de Antropología e Historia”.

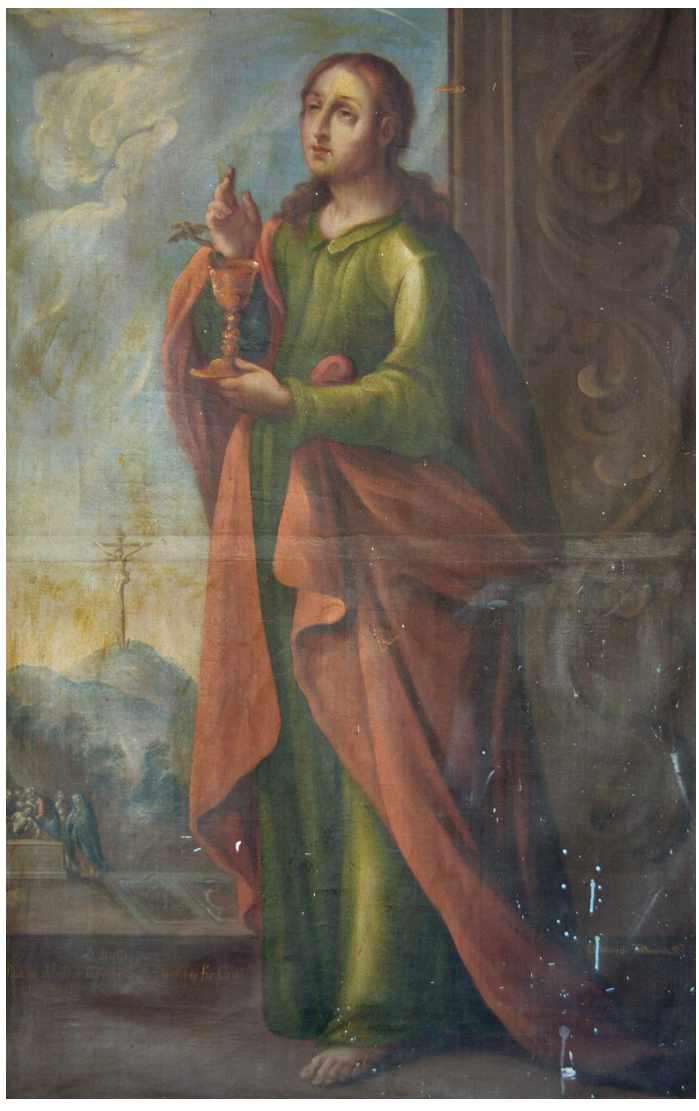

sén a la obra de Toussaint, se menciona a un pintor llamado Juan de Miranda (activo en I697-I7II), quien se encargó de algunos avalúos de cuadros pertenecientes a Benito Gómez de Barbosa en I698, otros lienzos propiedad de los capitanes Juan de Lobera Otañez en I7O2 y aquellos pertenecientes a Joseph Jaime en I7II. ${ }^{20}$ Asimismo, se menciona que este Miranda fue el autor de un retrato de Sor Juana Inés de la Cruz, propiedad de Gustavo Espinoza Mireles, del cual Francisco de la Maza había hecho un estudio. El fichero de esta obra, hecho por Enrique Berlín, señala algunas noticias referentes al testamento del pintor fechado el I2 de octubre de I7I4. De hecho, se registra a Miranda como maestro pintor, vecino de la Ciudad de México e hijo de Antonio de Miranda

20. Toussaint, La pintura colonial, I45. 


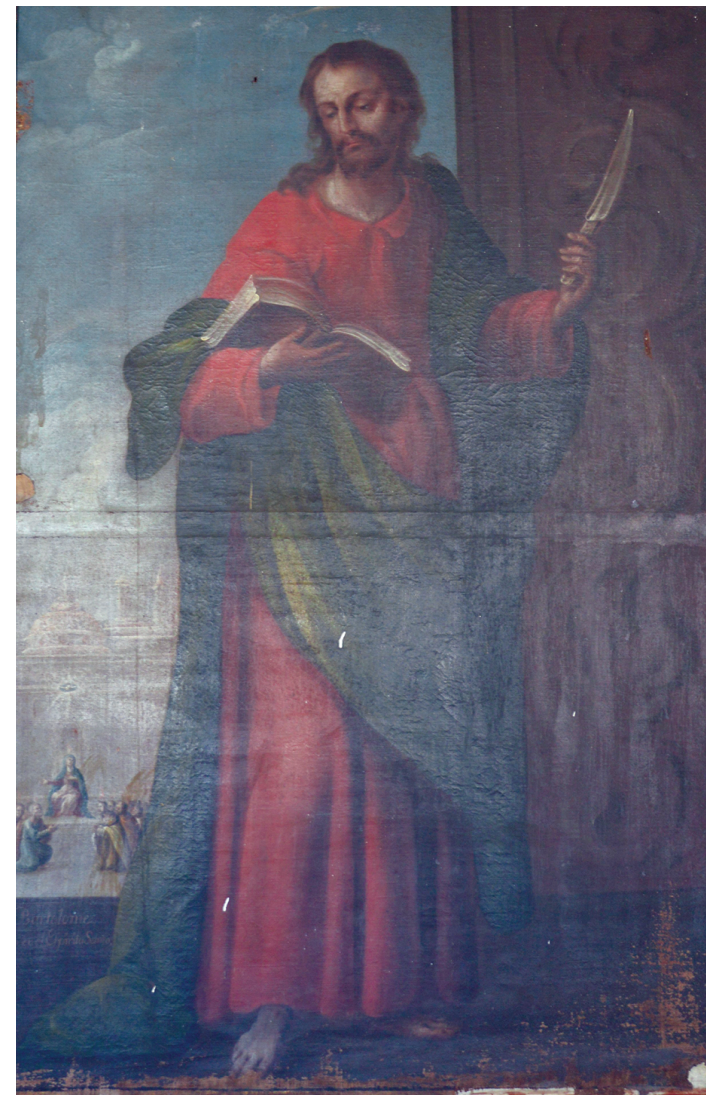

Fig. 3. Ventura de Miranda, San Bartolomé, primer tercio del siglo XviII, templo de Nuestra Señora de los Ángeles, Durango. Foto: Adolfo Martínez Romero. SECRETARÍA DE CULTURA-INAHMÉx. "Reproducción autorizada por el Instituto Nacional de Antropología e Historia”.

y Nicolasa Ramírez. Desafortunadamente, no tuvo descendencia y murió el 29 de octubre de ese mismo año. ${ }^{21}$

De acuerdo con lo anterior, por ahora no es posible relacionar a Ventura de Miranda con ninguno de los pintores mencionados antes. Las primeras noticias seguras que se tienen de este maestro fueron tomadas a partir de un avalúo de algunos cuadros que pertenecieron a Manuel Herrera. Así lo mencionó Toussaint, quien además advirtió que él mismo tenía un cuadro pequeñito entre sus pertenencias. ${ }^{22}$ Otras obras que se conocen de este pintor son las que se encuentran en una de las capillas de la Catedral de Méxi-

2I. Toussaint, La pintura colonial, 263.

22. Toussaint, La pintura colonial, I45. 
DOI: http://dx.doi.org/10.22201/iie.18703062e.2019.115.2698

254

ADOLFO MARTÍNEZ ROMERO

Fig. 4. Ventura de Miranda, San Simón, primer tercio del siglo XviII, templo de San Juan de Dios, Durango. Foto: Adolfo Martínez Romero. SECRETARÍA DE CULTURA-INAH-MÉX. "Reproducción autorizada por el Instituto Nacional de Antropología e Historia”.

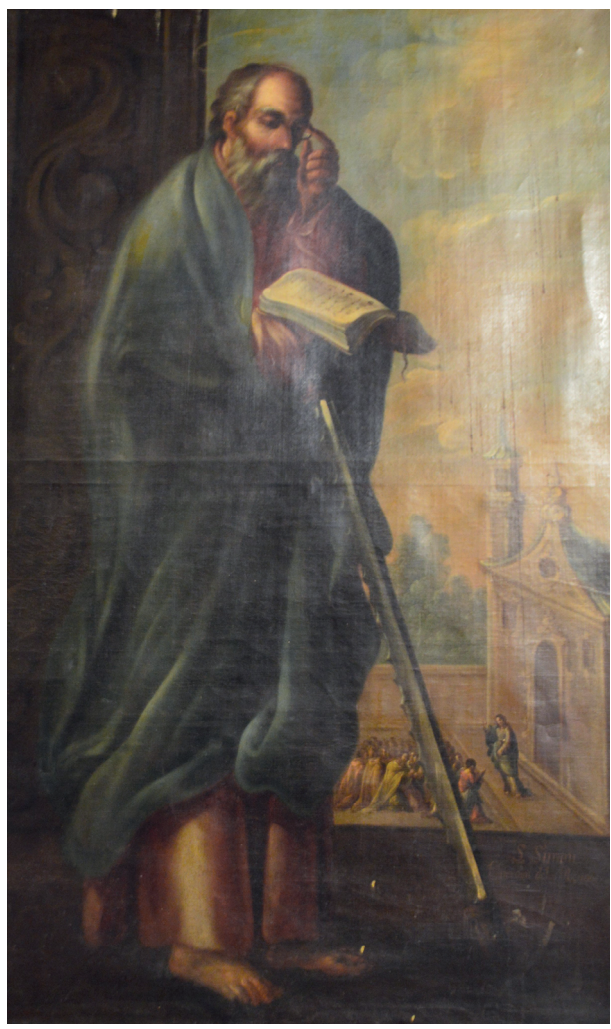

co, y que gracias a la importancia que tiene el recinto no pasaron inadvertidas a los ojos de los numerosos estudiosos que se han ocupado del inmueble. Los lienzos firmados por Ventura de Miranda adornan el intradós del arco de entrada de la capilla del Santo Cristo y de las Reliquias en la Catedral Metropolitana. Se trata de una serie que representa a ocho personajes del Antiguo Testamento que portan los símbolos pasionarios y que, según Magdalena Vences, deben entenderse como prefiguras de Cristo: Salomón y Jacob; Isaac y Zacarías; David y Moisés; y por último, Habacuc y Joseph. Asimismo, es suya una serie de pequeños ángeles que juegan con los símbolos pasionarios ${ }^{23}$ y un lienzo de la Vir-

23. Magdalena Vences, "La capilla del Santo Cristo y de Reliquias", en La Catedral de México. Patrimonio artístico y cultural (México: Secretaría de Desarrollo Urbano y Ecología/Fomento Cultural Banamex, 1986), 352. 


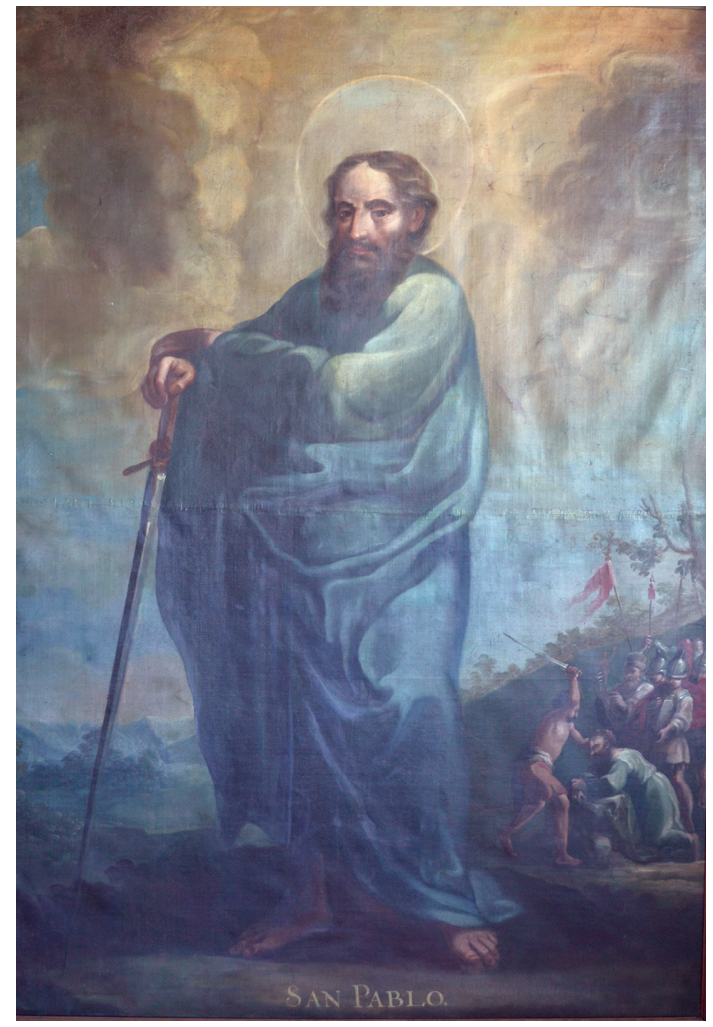

Fig. 5. Anónimo, San Pablo, primer tercio del siglo XVIII, templo de Nuestra Seńora de los Ángeles, Durango. Foto: Adolfo Martínez Romero. SECRETARÍA DE CULTURA-INAH-MÉX. "Reproducción autorizada por el Instituto Nacional de Antropología e Historia”.

gen de los Dolores colocado debajo de la clave del arco. Se ignoran más datos sobre estos lienzos.

También, para el caso de las pinturas de Miranda en Durango (figs. 2-5), se desconocen mayores datos, sólo que estuvieron en el convento franciscano. Los lienzos que llegaron hasta el presente son cuatro y sin duda formaron una serie dedicada a los apóstoles: los tres primeros se ubican en el templo de Nuestra Señora de los Ángeles (San Tadeo, San Juan Evangelista y San Bartolomé) y el otro se halla en el templo de San Juan de Dios (San Simón). Esta serie tiene deudas compositivas e iconográficas con la estética de su tiempo. Por ejemplo, se conoce que desde finales del siglo XvII, los pintores venían representando figuras de cuerpo completo al centro de la composición, utilizando el resto del espacio para incluir paisajes y cielos muy luminosos. El uso de figuras al centro y de tamaño casi natural pretendió la exaltación de estos personajes, lo que, sin 
Fig. 6. Anónimo, San Pedro, primer tercio del siglo XviII, templo de Nuestra Seńora de los Ángeles, Durango.

Foto: Adolfo Martínez

Romero. SECRETARÍA DE CULTURA-INAH-MÉX.

"Reproducción autorizada por el Instituto Nacional de Antropología e Historia”.

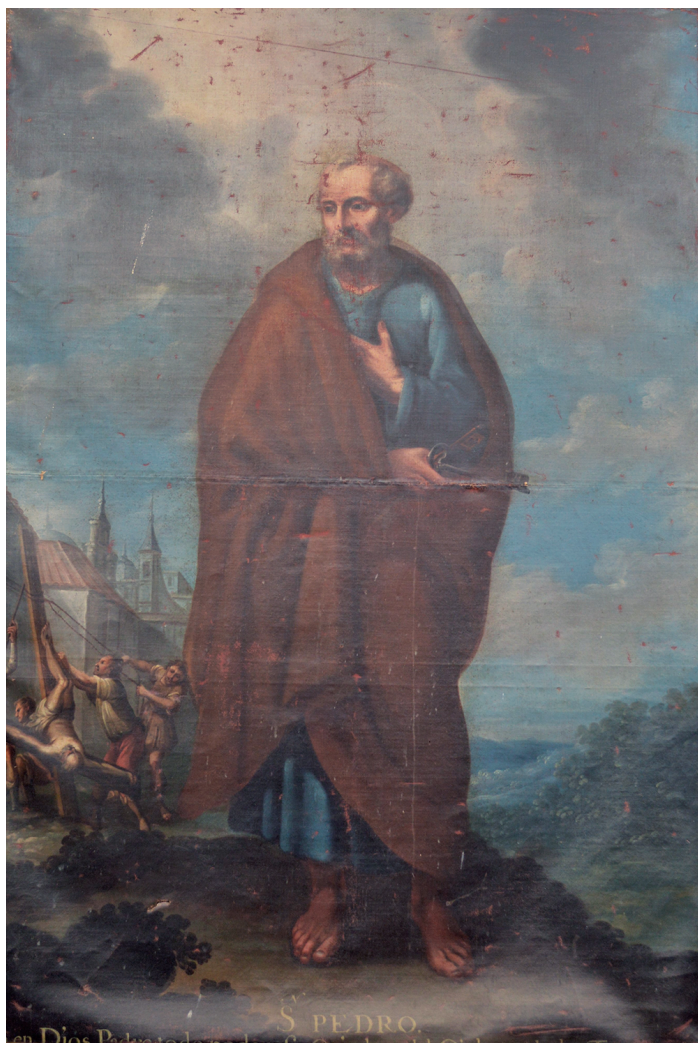

duda, fue el recurso más idóneo para terrenalizar a estos santos. Es cierto que el origen de estas composiciones se halla en grabados de Jan Sadeler I, Hendrick Goltzius, Hieronymus Wierix, Jacobo Callot y Lucas de Leyde que circularon en la Nueva España, pero fue hasta finales del siglo xvir cuando los pintores las reutilizaron, entre ellos, Juan Correa. ${ }^{24}$ De Correa, basta admirar los lienzos de los apóstoles que se encuentran en la catedral de San José en la Antigua Guatemala. El apostolado de Ventura de Miranda mantiene esta composición para resaltar la figura central. Además, cada uno de ellos porta el instrumen-

24. En los acervos de la Academia de San Carlos hay algunos grabados de Leyde sobre los apóstoles representados de cuerpo completo, así como algunos que contienen las palabras del Credo. Véase Abelardo Carrillo y Gariel, Grabados de la colección de la Academia de San Carlos (Ciudad de México: Universidad Nacional Autónoma de México, 1982). 


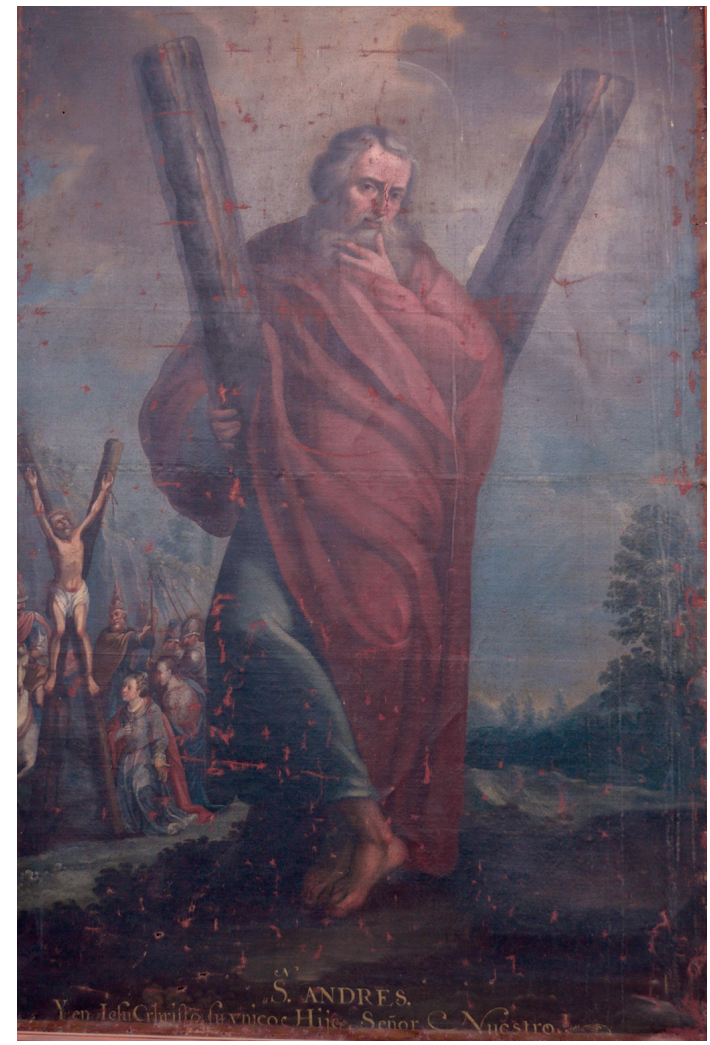

Fig. 7. Anónimo, San Andrés, primer tercio del siglo XviII, templo de Nuestra Seńora de los Ángeles, Durango. Foto: Adolfo Martínez Romero. SECRETARÍA DE CULTURA-INAHMÉx. "Reproducción autorizada por el Instituto Nacional de Antropología e Historia”.

to de su martirio. En la parte inferior de los lienzos y en un segundo plano, se observan escenas relacionadas con los artículos del Credo, oración que se dice fue compuesta por los apóstoles. Por ejemplo, el lienzo de San Tadeo se refiere al décimotercer artículo sobre la resurrección de la carne, por esto, se aprecia a un grupo de personas muertas que están en pleno proceso de resurrección, el cual es presidido desde las alturas por Dios Padre, auxiliado por dos querubines, quienes no cesan de tocar la trompeta del Juicio Final (fig. I). El artículo de san Juan Evangelista dice "padeció debajo del poder de Poncio Pilato, fue crucificado, muerto y sepultado". La escena igualmente se refiere al momento en que Jesús está siendo sepultado (fig. 2). Según el padre Jerónimo de Ripalda en su catecismo, san Juan, el discípulo más amado de Jesús, estuvo en la curación de la suegra de san Pedro, en la resurrección de la hija de Jayro, en la transfiguración del Tabor y en el Getsemaní y en la cena estuvo recostado 
Fig. 8. Anónimo, Santiago el

Mayor, primer tercio del siglo xviıI, templo de Nuestra Señora de los Ángeles, Durango. Foto: Adolfo Martínez Romero. SECRETARÍA DE CULTURA-INAHMÉx. "Reproducción autorizada por el Instituto Nacional de Antropología e Historia”.

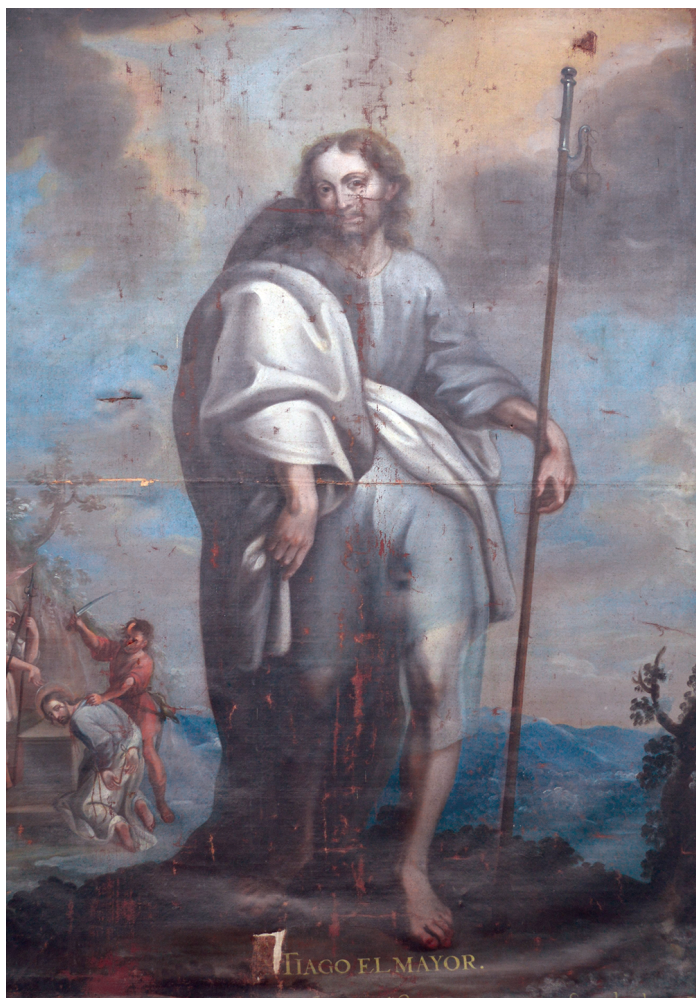

sobre el pecho de Jesús. ${ }^{25}$ El lienzo de San Bartolomé representa en la pequeña escena del lado izquierdo a la Virgen María sentada sobre un pedestal y debajo de ella a los I2 apóstoles en la escena del Pentecostés, por esto la inscripción dice: "Creo en el Espíritu Santo" (fig. 3). Por último, en el de San Simón, que es representado con su tradicional sierra, se puede observar a Jesús a la puerta del templo predicando y en la inscripción se lee: "el perdón de los pecados" (fig. 4).

El Credo se vio como un símbolo de la fe desde tiempos tempranos del cristianismo, pero se reforzó desde el Concilio de Trento con el objetivo de hacer

25. Catecismo de los padres Ripalda y Astete, adornado con I54 láminas finas e ilustrado con otras tantas esplicaciones parafrásticas para la mejor inteligencia de los dogmas y misterios de nuestra religión. Tomo III (Madrid: Imprenta de la Administración del Real Arbitrio de Beneficencia, 1800). Disponible en https://books.google.com.mx/books?id=S2ZQAAAACAAJ \& printsec=frontcover\& $\mathrm{dq}=$ catecismo $+\mathrm{de}+$ ripalda\&hl=es-4I9\&sa=x\&ved=oahuKEwjSn8vro6POAhUCPD4KHRyAChuQ 6AEIGjAA\#v=onepage \&q=catecismo\%20de\%2oripalda\&f=false (consultado en junio de 20I6). 


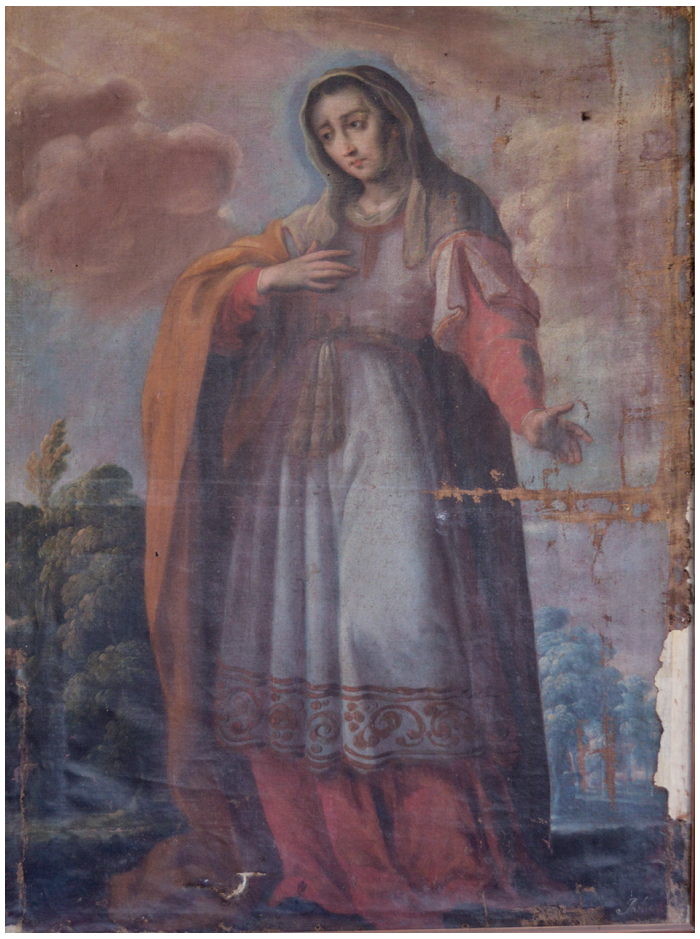

Fig. 9. Arellano, Santa Ana, primer tercio del siglo XVIII, templo de Nuestra Señora de los Ángeles, Durango. Foto: Adolfo Martínez Romero. SECRETARÍA DE CULTURA-INAHMÉx. "Reproducción autorizada por el Instituto Nacional de Antropología e Historia”.

un paralelismo entre el apostolado de quienes siguieron a Jesús y los obispos, quienes se perfilaban como los guías espirituales de la reformada Iglesia católica. Para esto, en I59I se publicó la Declaración del credo y símbolo de los apóstoles de Juan de Ribera, arzobispo de Sevilla, el cual explica que:

el credo y símbolo de los apóstoles es la lúbre del ánima, y el cumplimiento de los que creen. En éste se enseńa la unidad, y la Trinidad distinta en las personas. En éste se da a entender la bondad del Creador y la misericordia del Redentor, y la gracia del Espíritu Santo consolador. Por éste se aparta la infidelidad, se abre la puerta de la vida, y se manifiesta nuestra concesión. El símbolo es breve de palabras, mas es profundo de misterios. Es pequeño, porque no confunda la memoria; mas es grande, porque traspasa el entendimiento de cualquier hombre: porque todo lo que está figurado en los Patriarcas, anunciado y escrito en las escrituras sagradas, predicado por los Profetas; ahora sea del eterno Padre, ahora sea de su unigénito Hijo, o del Espíritu Santo, ahora sea del misterio de la Encarnación del Verbo divino hijo de Dios, o de 
la muerte del Señor, o del misterio de la Resurrección, todo está comprehendido brevemente en este símbolo. ${ }^{26}$

No hay duda, esta representación de los apóstoles relacionados con el Credo se difunde en la Nueva Vizcaya cuando, por un lado, el clero secular comenzó a estabilizar sus rentas tras el control de los ataques e insurrecciones y el aumento demográfico en la región mientras por otro lado, los misioneros jesuitas y franciscanos tuvieron un avance sustancial en la evangelización más allá de la Nueva Vizcaya. ${ }^{27}$

El segundo grupo de lienzos de un apostolado que se halla en el templo de Nuestra Señora de los Ángeles, del cual se desconoce su autor, está conformado por cuatro lienzos: San Pablo, San Pedro, San Andrés y Santiago el Mayor (figs. 5-8). Igual que la serie de Miranda, las inscripciones que tiene en la parte inferior señalan las frases del Credo. Esta serie de lienzos se destaca por la utilización de colores suaves, cálidos, sin contrastes fuertes de luz, además de haber sido pintados con una capa pictórica muy delgada que permite, en casi todos los casos, apreciar la base de preparación. Asimismo, mantiene una composición similar a la de Miranda: figuras de cuerpo completo al centro, portando símbolos o atributos que los caracterizan; la única diferencia es que las pequeñas escenas secundarias de estos lienzos situadas en uno de los costados tratan sobre el momento del martirio que padecieron cada uno de ellos.

La figura de Santiago el Mayor aparece al centro y se destaca por los giros que da su cuerpo y los escorzos que intentó realizar el pintor, tanto el de la pierna izquierda como el del brazo derecho reflejan el deficiente manejo de este recurso. Sin embargo, el trabajo hecho en el rostro evidencia un buen dibujo anatómico. Del lado izquierdo aparece la escena donde se muestra el momento en que los soldados proceden a degollarlo. La inscripción que tiene en la parte inferior es difícil de apreciar, debido a que el marco que se le colocó en épocas recientes impide su visualización. Sin embargo, y de acuerdo con su artículo debe de leerse, aunque con algunas variaciones: "que fue concebido por el

26. Juan de Ribera, Declaración del credo y simbolo de los apóstoles y de la oración del Pater noster $y$ de los precetos de Caridad amor de Dios, y del próximo, y de los diez mandamientos de la ley de Dios; en que se contiene todo lo que el Christiano ha de creer, desear y obrar (Madrid: Imprenta de Luis Sánchez, I59I). Disponible en https://books.google.com.mx/books?id=oiHLzaeuYkIc\&printsec=f rontcover\&source=gbs_ge_summary_r\&cad=o\#v=onepage\&false (consultado en junio de 2016).

27. Bárbara Meyer de Stinglhamber, Arte sacro de Baja California Sur: siglos XVII-XIX: objetos de culto y documentos (Ciudad de México: Instituto Nacional de Antropología e Historia, 200I). 
espíritu santo y nació de Santa María Virgen”. La pintura de San Andrés curiosamente lo representa de pie, cruzado de piernas y montado sobre su cruz. En la inscripción se lee: "Y en JesuCristo su único, hijo, Señor Nuestro". La figura de San Pedro sostiene las llaves del cielo con la mano derecha, mientras que la otra la mantiene pegada al pecho en medio de un grueso y amplio ropaje. La escena secundaria presenta el momento de su crucifixión. En la parte inferior tiene la inscripción: "Creo en Dios Padre Todopoderoso Creador del Cielo y de la Tierra”. La inscripción de la pintura de San Pablo no puede verse por el marco que está encima de ella.

Como se mencionó al inicio de este trabajo, también dentro del acervo pictórico que posee este templo de Nuestra Señora de los Ángeles se encuentra una pintura de Santa Ana (fig. 9) firmada por uno de los Arellano. Al parecer ningún otro lienzo de este acervo puede relacionarse con esta familia de pintores, de quienes poco se ha estudiado, como tampoco puede atribuírsele a este Arellano los lienzos anónimos de los apóstoles, esto debido a que presenta características diferentes. ${ }^{28}$ Arellano, al igual que muchos pintores activos a principios del siglo XVIII, ha sido poco atendido. Como anotó Mirta Isaurralde en su estudio sobre los Arellano, algunos datos importantes se han venido recogiendo por los especialistas; por ejemplo, señala que Elisa Vargaslugo, en su monumental obra sobre Correa, fue quien destacó la participación de Antonio de Arellano, fundador de esta dinastía, dentro del gremio de pintores como veedor del arte de la pintura. Asimismo, señala que fue Rogelio Ruiz Gomar quien confirmó que Antonio y Manuel, ambos de apellido Arellano, eran padre e hijo. ${ }^{29}$ Así, a partir de que ha ido creciendo la información sobre estos maestros, han surgido nuevas investigaciones que intentan aclarar aún este panorama en torno a esta familia. Dentro de una colección particular en Durango, propiedad de Federico Schroeder, se localizaron otros tres lienzos: uno de san Jerónimo, firmado por un Arellano, quizá el mismo que pintó a

28. Toussaint, La pintura colonial en México, I45.

29. Mirta Asunción Insaurral de Caballero, "El purgatorio como asunto pictórico. Texto, materia e imagen en una alegoría de Arellano", tesis de Maestría (Ciudad de México: Universidad Nacional Autónoma de México/Facultad de Filosofía y Letras, 20II); Rosa María Uribe Rivera, "Tepepan, arte e historia", tesis de Maestría (Ciudad de México: Universidad Nacional Autónoma de México/Facultad de Filosofía y Letras, 1998); Gabriela Davayane Amaro Ortega, "La vista en la plaza: el fenómeno de las vistas de plazas en la Ciudad de México del siglo xvin", tesis de Maestría (Ciudad de México: Universidad Nacional Autónoma de México-Facultad de Filosofía y Letras, 2000). 
DOI: http://dx.doi.org/10.22201/iie.18703062e.2019.115.2698

262

ADOLFO MARTÍNEZ ROMERO

Fig. Io. Anónimo, primer tercio del siglo XVIII, colección particular, Durango. Foto: Adolfo Martínez Romero. SECRETARÍA DE CULTURA-INAHMÉx. "Reproducción autorizada por el Instituto Nacional de Antropología e Historia”.

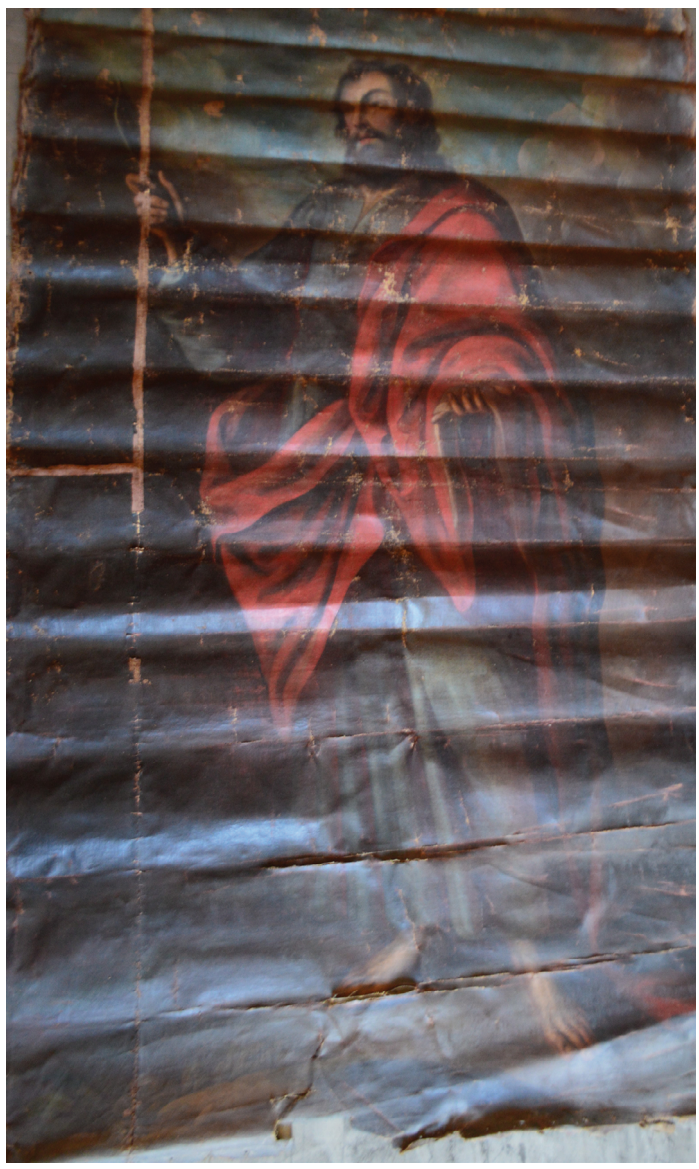

Santa Ana, otro de San Roque, anónimo (fig. II), y otro más sin identificar (fig. Io), también anónimo. Los tres estaban en muy mal estado de conservación, debido a que estuvieron enrollados y doblados bajo un gran bulto de papeles. Hoy se desconoce el paradero de estos lienzos porque fueron sustraídos en meses recientes.

También dentro de esta colección estaban dos lienzos que fueron parte de otra serie más de apóstoles. Se trataba de las pinturas de San Pedro y San Pablo, las cuales hoy sólo se conocen por medio de fotografías (fig. I3). Afortunadamente, en la colección particular de los Garcinava se encontró una pintura de San Judas Tadeo (fig. I2) firmada por Nicolás Correa en I728, la cual, aten- 


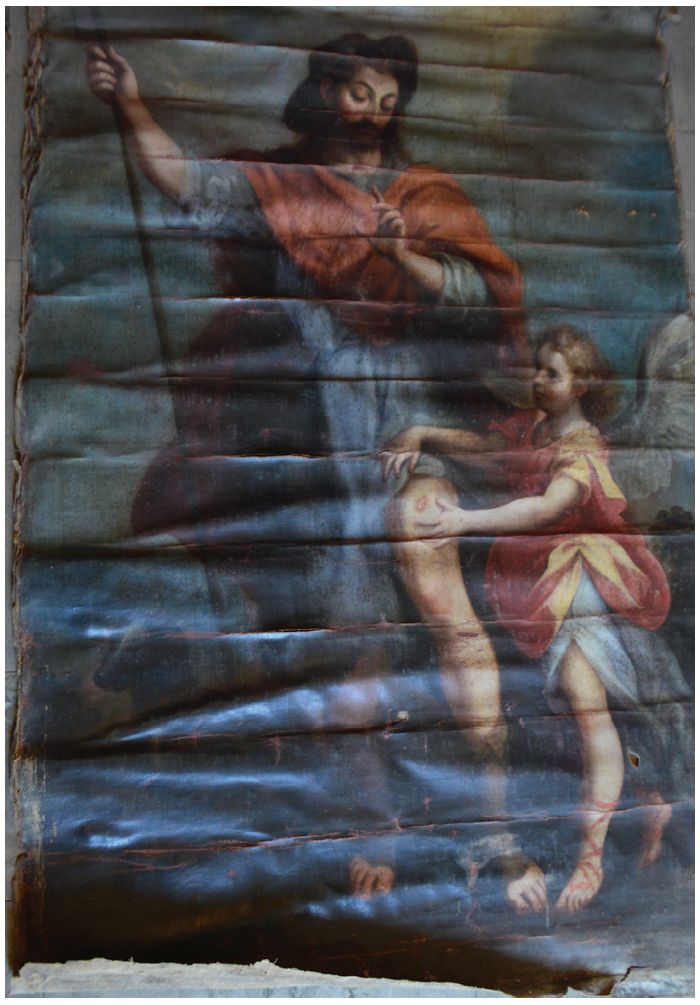

Fig. II. Anónimo, San Roque, primer tercio del siglo XVIII, colección particular, Durango. Foto: Adolfo Martínez Romero. SECRETARÍA DE CULTURA-INAHMÉx. "Reproducción autorizada por el Instituto Nacional de Antropología e Historia”.

diendo a las características formales de los lienzos anteriores de San Pedro y San Pablo, no hay duda de que forman parte de una misma serie. No es difícil pensar que estos lienzos hayan pertenecido a uno de los templos de la ciudad, como sucedió con otras pinturas que salieron en diferentes épocas. Por ejemplo, Luciano Veyán, un prominente vecino de la ciudad de Durango, compró hacia I880 algunas obras pictóricas del acervo de los juaninos, entre ellas, una Virgen de los Dolores y una Virgen del Tránsito, esta última de la autoría de José de la Mota (I716). No es seguro que esta pintura haya sido parte de aquellos lienzos de "valiente pincel" que se enviaron desde la Ciudad de México para colocarlos en el claustro en $1729^{30}$ o que haya sido parte del retablo de Nuestra Señora del Tránsito que se estrenó el 7 de marzo de 1739 en la iglesia de San

30. Gacetas de México, 201. 
DOI: http://dx.doi.org/10.22201/iie.18703062e.2019.115.2698

264 ADOLFO MARTÍNEZ ROMERO

Fig. I2. Nicolás Correa, San Judas Tadeo, i728, colección particular, Durango. Foto: Adolfo Martínez Romero. SECRETARÍA DE CULTURA-INAHMÉx. "Reproducción autorizada por el Instituto Nacional de Antropología e Historia”.

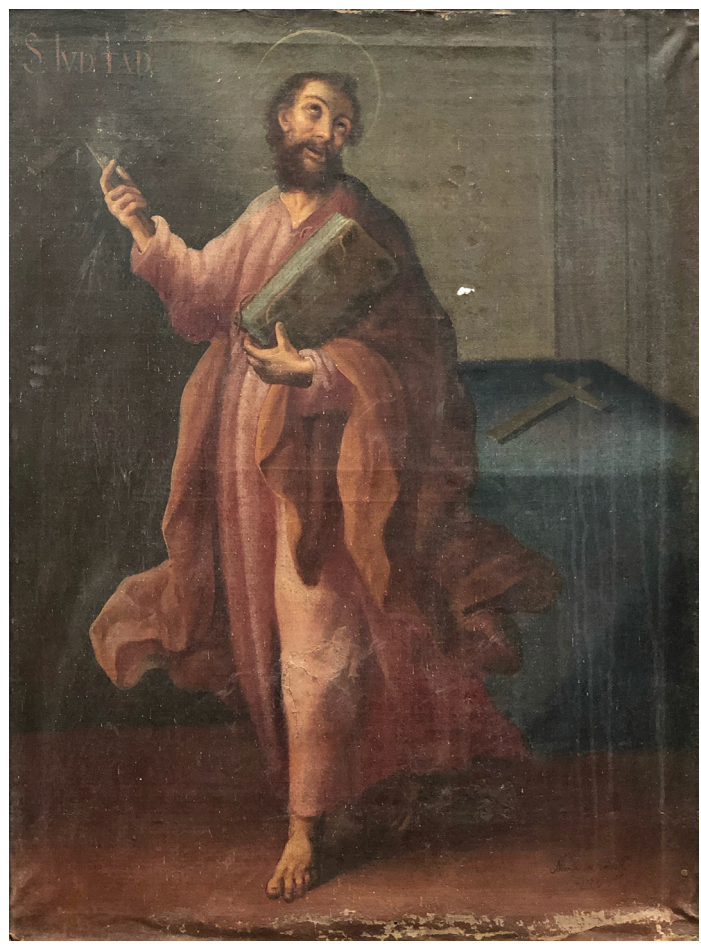

Juan de Dios. ${ }^{3 \mathrm{I}}$ Hoy, esta pintura de la Virgen del Tránsito la posee uno de losdescendientes de Luciano Veyán.

Los lienzos de Nicolás Correa tienen una composición similar a la de aquellos lienzos de los apóstoles mencionados previamente, en los que las figuras de estos personajes se presentan al centro, sin embargo, la diferencia es que Correa los situó dentro de espacios cerrados y no en el exterior. Igualmente, los apóstoles sostienen los objetos que permiten su identificación. Por ejemplo, san Pedro porta un par de llaves, san Pablo una espada y san Judas Tadeo una escuadra de carpintero que lo identificó por lo menos hasta el siglo XIX, antes de la aparición de la vela en su cabeza. Se sabe que Nicolás fue hijo de José Correa y, por consiguiente, sobrino de Juan Correa, miembros de la afamada familia de pintores mulatos. Además, Nicolás destaca dentro de la his-

31. Gacetas de México, 172. 


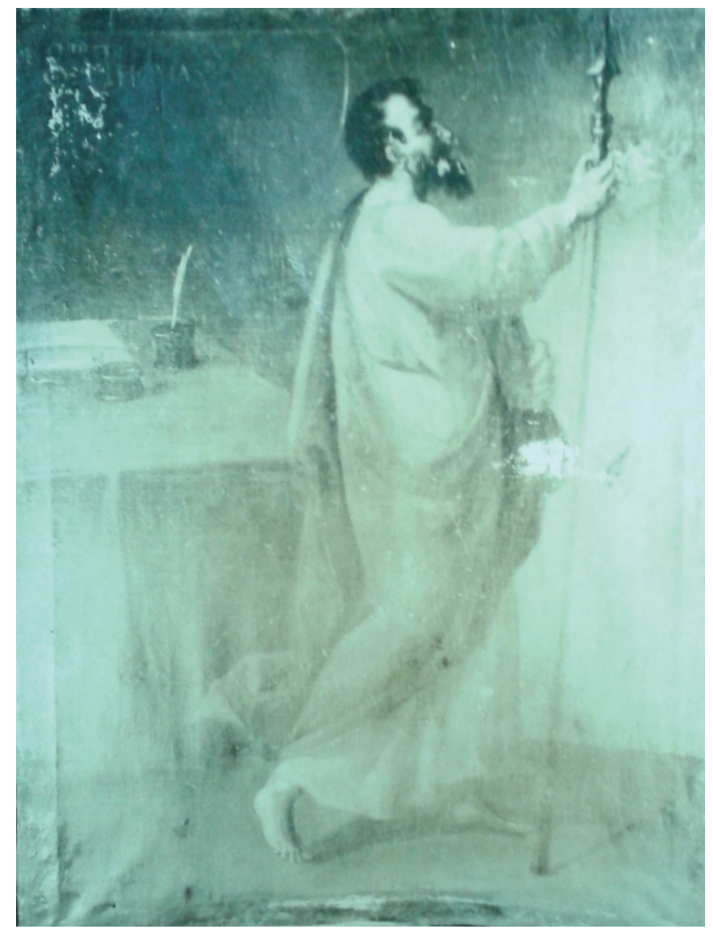

Fig. I3. Nicolás Correa, San Pedro, primer tercio del siglo xviII, Durango. Foto: Adolfo Martínez Romero. SECRETARÍA DE CULTURA-INAH-MÉX.

"Reproducción autorizada por el Instituto Nacional de Antropología e Historia”.

toria de la pintura novohispana por su incursión en los trabajos pictóricos con incrustación de concha. ${ }^{32}$

Finalmente, con el propósito de establecer el origen de los apostolados incompletos que se encuentran en el templo de Nuestra Señora de los Ángeles, se puede decir que pertenecieron al convento franciscano, si se atiende al hecho de que sus bienes pasaron a la catedral en 1917 para luego ser entregados de nuevo a los religiosos cuando retornaron a la ciudad en 1942, y se instalaron en el templo de los Ángeles. Esto se evidencia en el inventario que realizó el guardián Mirablanca donde se señala la existencia de varios apostolados, aunque parece que ya incompletos desde ese entonces, debido a que no se

32. Sonia Ocaña Ruiz, "Nuevas reflexiones sobre las pinturas incrustadas de concha y el trabajo de Juan y Miguel González", Anales del Instituto de Investigaciones Estéticas XXIV, núm. IO2 (20I3): I25-I76; Sonia Ocaña Ruiz, "Láminas de concha: un caso de autonomía en la pintura novohispana de los siglos xvıı y Xvıı", tesis de Doctorado (México: Universidad Nacional Autónoma de México-Facultad de Filosofía y Letras, 20II). 
cuentan ni siquiera I2 pinturas de una misma serie en el documento. Por ejemplo, sólo se menciona que, sin especificar su lugar dentro del recinto franciscano, había algunas "pinturas antiguas al óleo sin marco de una Cena del Señor, un San Andrés, un San Pablo, un San Juan Bautista, una Purisima Concepción, un Santiago el Mayor, un San Bernabé, un San Felipe y un San Simón” y otras tres sin nombre. Asimismo, este inventario registra otras pinturas que tienen marcos de madera, entre ellas, las de "Nuestra Señora de Guadalupe, Nuestra Señora de la Soledad, Purísima Concepción, así como los apóstoles San Juan Evangelista, San Felipe, San Francisco, San Tadeo, San Bartolomé y San Simón”. Si el origen de estos lienzos está en el convento franciscano, pudiera decirse que el gusto de los franciscanos por la obra de estos pintores (Ventura de Miranda y Arellano) fue una realidad, sin embargo, será necesario tener mayores elementos que puedan confirmar esta situación, además quedará pendiente la localización de más obras que puedan acrecentar el conocimiento que tenemos de ellos. Respecto al apostolado firmado por Nicolás Correa, no puede decirse nada más concreto debido a que no se sabe con exactitud cómo llegaron a las colecciones Schroeder y Garcinava.

\section{Conclusiones}

En los últimos años se ha puesto atención en los pintores del siglo XviII y sus obras. El primero en atender este periodo fue Abelardo Carrillo y Gariel, quien realizó un estudio sobre Miguel Cabrera. Desde entonces han salido a la luz pública tesis doctorales y artículos académicos sobre otros pintores. Hoy, el norte y sus objetos son y serán parte importante de la revaloración de la pintura novohispana dieciochesca, debido a que la mayoría de los pintores activos durante la primera mitad del siglo Xvin encontraron su veta de oportunidad en esta región. Afortunadamente, es grande el número de obras pictóricas de estos maestros que se encuentran en los diferentes recintos religiosos y museísticos. Para el caso de los lienzos abordados en este trabajo, era urgente dar a conocer estas noticias para acrecentar el conocimiento de la pintura novohispana, pero también ante la serie de "restauraciones" que desde 2015 hicieron los estudiantes y maestros de la Escuela de Pintura, Escultura y Artesanías de la Universidad Juárez del Estado de Durango, quienes no cuentan con los conocimientos necesarios para dichos trabajos de restauración y conservación. Lamentablemente fue tibia la actuación del Instituto Nacional de Antropología e Historia-Durango, a pesar de haber tenido conocimiento de ello. \$ 